\title{
Detection of Dinophysis species and associated okadaic acid in farmed shellfish: a two-year study from the western Mediterranean area
}

\author{
Anna Maria Bazzoni, Alessandro G. Mudadu, Giuseppa Lorenzoni, Barbara Soro, \\ Nadia Bardino, Igor Arras, Giovanna Sanna, Bruna Vodret, Riccardo Bazzardi, \\ Edoardo Marongiu, Sebastiano Virgilio
}

Veterinary Public Health Institute of Sardinia, 07100 Sassari, Italy

ambazzoni@gmail.com

Received: February 16, 2018 Accepted: June 14, 2018

\begin{abstract}
Introduction: Diarrhoetic shellfish poisoning (DSP), an alimentary intoxication known to lead to intestinal symptoms, and caused by toxins produced by some dinoflagellates (including several Dinophysis), represents a serious threat to public health. The aim of this paper was to provide information about the occurrence and abundance of potentially toxic harmful algal species causing DSP, and the associated concentration of okadaic acid (OA) toxins. The departing assumption was that in the study area there was an increase in the presence both of Dinophysis species and OA and its derivates that could result in a risk to the health of seafood consumers. Material and Methods: During 2015-2016, water and shellfish samples were collected in the Mediterranean area (Sardinia, Italy). Dinophysis cells were counted according to Utermöhl's method from water samples, while mass spectrometry was used to identify lipophilic toxins in molluscs. Results: A total of 46 non-compliant samples of Mytilus galloprovincialis were observed. Their non-compliance concerned their OA levels above the legal limit. Among toxic dinoflagellates, D. acuminata and D. sacculus were the species found mostly during DSP events. Conclusion: No cases of human intoxication have been reported, but continuous surveillance of toxic phytoplankton is necessary to predict and prevent its harmful effects on human health.
\end{abstract}

Keywords: shellfish, lipophilic biotoxins, Dinophysis acuminata, Dinophysis sacculus, Sardinia.

\section{Introduction}

Diarrhoetic shellfish poisoning (DSP) is an alimentary intoxication that can cause intestinal symptoms such as diarrhoea, nausea, vomiting, and abdominal pain in seafood consumers $(24,23)$. DSP has a high incidence that is increasing worldwide (7), representing a constant threat to public health. This poisoning is caused by a suite of toxins produced by some cosmopolitan microalgae belonging to the Dinophyceae class, including several Dinophysis and some benthic Prorocentrum species. Dinophysis includes a number of species distributed worldwide, 10 of which are able to synthesise diarrhoeic shellfish toxins (DST) (23), heat-stable and lipophilic polyether phycotoxins that include okadaic acid (OA) and dinophysistoxin derivatives (DTXs). The lipophilic toxins also include azaspiracids (AZAs), yessotoxins (YTXs), and pectenotoxins (PTXs). Seven of the DST analogues can cause DSP syndrome $(22,23)$. Dinophysis is considered the main source of DSP toxins in various species of shellfish, mainly filter-feeding bivalve molluscs such as mussels, scallops, clams, and oysters. In a number of countries, Dinophysis is one of the potentially high-risk genera for biotoxicity events. The impact of its presence can range from very mild to extremely toxic.

The present study was performed in shellfish farming areas of Sardinia (Italy, the Western Mediterranean Sea) and based on the results of a monitoring programme in 2015-2016. Its aim is to provide information about the occurrence and abundance of Dinophysis species and associated concentrations of DSP toxins that could be present in the shellfish. In consideration of the relevant risk related to food security that may derive from the presence of potentially toxic harmful algal species (HAS) and potential consequent human poisoning, a monitoring programme has been operational in Sardinia since 1988 in order to protect the health of 
seafood consumer and the economic viability of aquaculture operators. Previous monitoring studies performed in aquaculture waters $(25,3)$ have revealed the presence of several potentially toxic HAS in Sardinia, some of which are widely distributed. The detection of different Dinophysis species is recurrent, but only a few of them (including Dinophysis acuminata Claparède \& Lachmann and Dinophysis sacculus Stein) occur on a regular basis (3). Despite the fact, DSP toxicity episodes in shellfish have been rare. Lugliè et al. (18) reported only three cases through 2011, while shellfish farm closures for paralytic shellfish poisoning (PSP) events were more common (17).

\section{Material and Methods}

Study area. Sardinia is an island located in the middle of the Western Mediterranean Sea (Fig. 1). It has relevant economic and social interests in bivalve production and aquaculture, the mussel farm industry covering a surface area of about 1,300 ha. Mollusc and fish farms are present along the coast, both in marine and transitional waters. The coasts are subjected to intense naval traffic as they lie on the main route taken by ships crossing the Mediterranean Sea. Several Sardinian lagoons have a high trophic status (21) and show large seasonal variations in nutrient concentration due to polluted inputs from the respective watersheds, resulting from the inadequate purification of urban and agricultural wastewater. Moreover, lagoons and wetlands have been extensively reclaimed for a variety of human uses that have led to profound changes in the hydrological conditions.

Monitoring. Based on the Sardinian Regional Monitoring Programme (26), water samples were collected from a total of 19 coastal sites during 2015 and 2016 in order to assess the presence and abundance of potentially toxic HAS, as described in the Intergovernmental Oceanographic Commission (IOC) Taxonomic Reference List of Toxic Plankton Algae (http://www.marinespecies.org/hab/) (14).

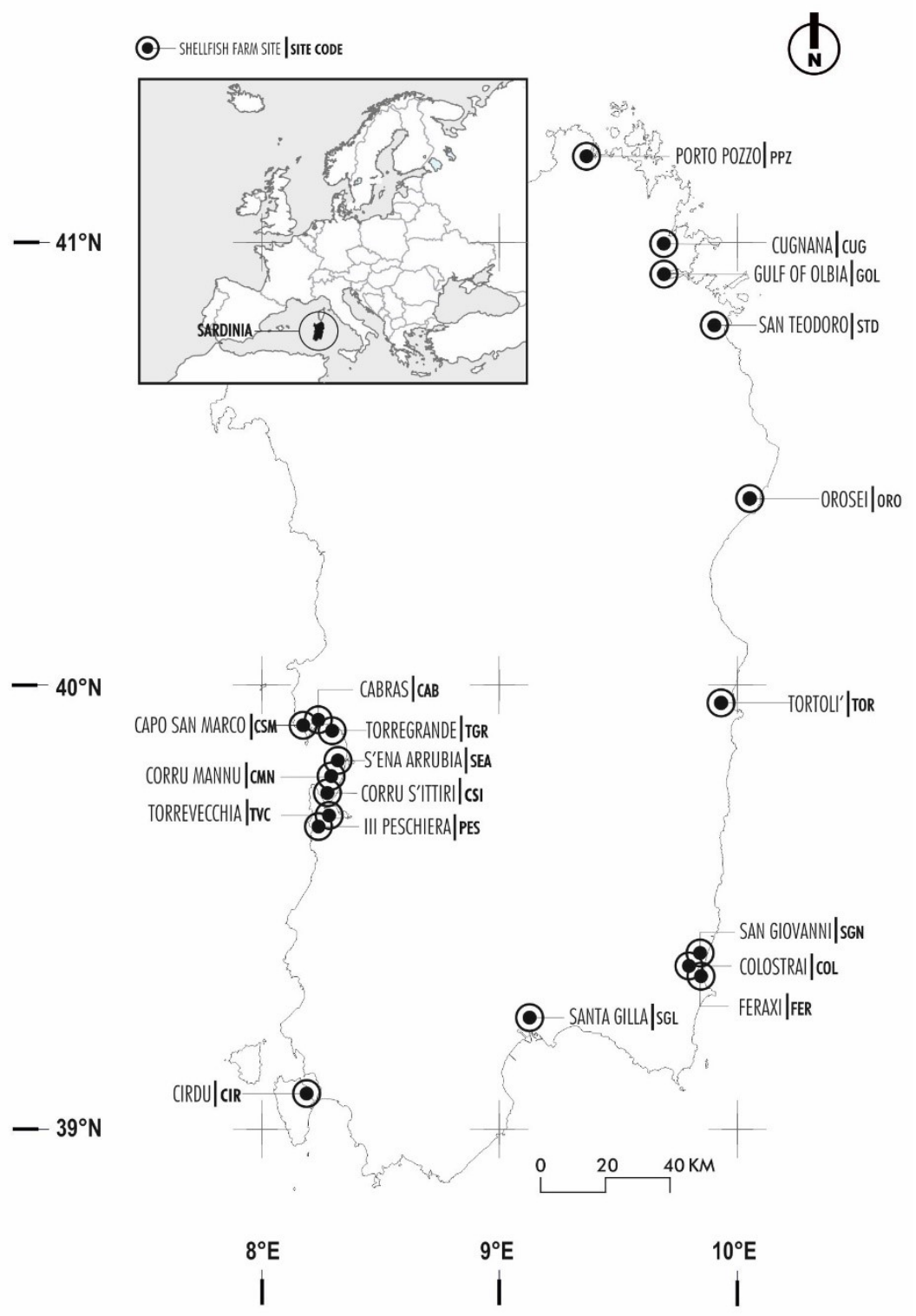

Fig. 1. Geographic locations of Sardinia and shellfish farm sampling sites (black circles) 
For each site, one to five stations were sampled. Samples were collected fortnightly. Because of the subsurface position of the mussels and the low mean depth (from 0.6 to $2 \mathrm{~m}$ ) of the majority of the farming sites (3), in transitional water samples were taken manually at a depth of about $0.5 \mathrm{~m}$ from the surface into clean polyethylene bottles (PE). In marine areas, where the depth is greater, three water samples (from the surface, half column, and bottom) were collected by Niskin bottle and mixed together to obtain an integrated sample. All samples were fixed with Lugol's iodine. Either on the day of water sample collection or after no more than two days, mussel samples were obtained for the evaluation of diarrhoetic, amnaesic, and paralytic toxins. At each site, $3 \mathrm{~kg}$ of molluscs of commercial size (8) were collected.

Although the data collected included the quantitative analyses of all HAS found in the water samples and concomitant biotoxin groups, the present paper considered only those results regarding Dinophysis species (particularly D. acuminata and D. sacculus) and the combined DSP toxins, which often exceeded the permitted limit in the current regulations (9). Dinophysis was the most important genus in terms of relative abundance and frequency and due to repeated occurrences of DSP events during the study period.

Dinophysis species analyses. The Dinophysis species were counted in fixed water samples $(1 \mathrm{~L})$. The cell count was performed according to Utermöhl's method (28) at $\times 200$ magnification using settling chambers (from 5 to $25 \mathrm{~cm}^{3}$ depending on phytoplankton cell abundance) under an inverted microscope (Olympus IX 73). When necessary, live samples were also observed for identification.

DSP toxin analyses. The shellfish samples harvested during 2015 and 2016 at the Sardinian monitoring areas were analysed to identify DSP toxins (OA, DTXs, PTXs, YTXs, and AZAs) by liquid chromatography coupled with tandem mass spectrometry (LC-MS/MS) in accordance with the official protocol (1) governed by EC Regulation $15 / 2011$ (10). Analyses were performed at the Veterinary Public Health Institutes (IZS) of Piemonte, Liguria and Valle D'Aosta, Genova during 2015, and at IZS of Sardinia, Sassari, in 2016. Briefly, an aliquot $(2 \mathrm{~g})$ of muscle tissue was homogenised with $9 \mathrm{~mL}$ of methanol. After shaking, the extract was centrifuged and the supernatant was transferred to a flask. The extraction was repeated a second time. The extracts were combined and brought to a final volume of $20 \mathrm{~mL}$ with methanol. The determination of OA, AZAs, and YTXs was performed after filtering an aliquot of the methanolic extract through a syringe filter $(0.45 \mu \mathrm{m}$ and $0.2 \mu \mathrm{m}$, respectively in 2015 and 2016) and injecting it into an LC-MS/MS instrument (Thermo Scientific TSQ Vantage in 2015 and AB SCIEX QTRAP 4500 in 2016). A second aliquot was subjected to basic hydrolysis for the determination of the total OA-DTX content. Next, $125 \mu \mathrm{L}$ of $2.5 \mathrm{M} \mathrm{NaOH}$ was added to $1 \mathrm{~mL}$ of extract and the mixture was heated at $76^{\circ} \mathrm{C}$ for $40 \mathrm{~min}$. Then, after cooling to room temperature, the mixture was neutralised with $125 \mu \mathrm{L}$ of $2.5 \mathrm{M} \mathrm{HCl}$ and shaken for $0.5 \mathrm{~min}$. This extract was filtered and injected into the LC-MS/MS instrument. The analysis was performed by high-performance liquid chromatography (HPLC), using a Thermo Scientific Accela 1250 pump in 2015 and a Perkin Elmer Flexar F15 in 2016. Chromatographic separation was obtained by a reversed phase HPLC column (Kinetex XB-C18 $100 \times 2.1 \mathrm{~mm}$ ID, $2.6 \mu \mathrm{m}$ from Phenomenex in 2015, and X BRIDGE BEH C18 $50 \mathrm{~mm} \times 2.1 \mathrm{~mm} \times 2.5 \mu \mathrm{m}$ in the WATERS range in 2016). Different eluents were used. IZS of Genova used $6.7 \mathrm{mM}$ of ammonia aqueous solution as eluent $\mathrm{A}$ and $6.7 \mathrm{mM}$ of ammonia solution in acetonitrile: water $90: 10 \mathrm{v} / \mathrm{v}$ as eluent $\mathrm{B}$, at a flow rate of $450 \mu \mathrm{L} / \mathrm{min}$; IZS of Sassari used $0.05 \mathrm{v} / \mathrm{v} \%$ ammonia in water at $\mathrm{pH} 11$ as eluent A, and $0.05 \mathrm{v} / \mathrm{v} \%$ in $90 \%$ acetonitrile as eluent B at a flow rate of $400 \mu \mathrm{L} / \mathrm{min}$. The analysis was carried out with a gradient elution and the injection volume was $5 \mu \mathrm{L}$. The mass spectral analysis was performed on a triple quadrupole mass spectrometer equipped with a heated ion spray interface (electrospray ionization ESI). Detection and quantification of molecules were performed by selected reaction monitoring (SRM) in 2015 and by multiple reaction monitoring (MRM) in 2016. The detection limit of this analytical method for the OA toxin group was $60 \mu \mathrm{g} \mathrm{OA} \mathrm{eq} / \mathrm{kg}$ e.p.

\section{Results}

During the two-year study, a total of 2,755 water samples (1,715 in 2015 and 1,040 in 2016) and 2,561 shellfish samples (1,365 in 2015 and 1,196 in 2016) were examined. The OA toxin group was identified in 81 analysed samples $(2.9 \%), 27(1.6 \%)$ having been detected in 2015 and 54 (5.2\%) in 2016. A total of 46 non-compliant samples with OA levels above the legal limit ( $160 \mu \mathrm{g} \mathrm{OA} \mathrm{eq} / \mathrm{kg}$ e.p.) were observed, as 23 each in 2015 and 2016 (Table 1). Positive samples were observed in the Feraxi (FER), Orosei (ORO), and Tortolì (TOR) sites during both 2015 and 2016. Positive samples were also found in 2015 in Colostrai (COL), Santa Gilla (SGL), and San Giovanni (SGN) and in 2016 in Cirdu (CIR) and San Teodoro (STD). During 2016, the OA toxin group was also found in Corru S'Ittiri (CSI), Golfo di Olbia (GOL), Peschiera (PES), and Torregrande (TRG), without toxin content exceeding the limits defined by law (Fig. 2).

The toxicity was dominated by the occurrence of the OA toxin group, while other components were rarely recorded. Specifically, in only a few cases (in TOR in January 2016 and in ORO in June 2016) PTX2 did cooccur with the OA toxin group, but never at high values; the maximum value was $122 \mu \mathrm{g}$ PTX2 eq $/ \mathrm{kg}$ e.p. in ORO, in coincidence with a toxic episode.

The results of HAS analyses showed that $D$. acuminata, followed by D. sacculus, were the species 
most frequently identified during the positive events, although at variable relative abundance (Table 1). Rarely, D. rotundata Claparède \& Lachmann and Prorocentrum mexicanum Osorio-Tafall were observed, always at negligible level of presence. D. acuminata and D. sacculus reached the highest values (almost $143 \times 10^{3}$ cell/ $\mathrm{L}$ and $38 \times 10^{3}$ cell/L, respectively) in TOR during 2015 , corresponding to an OA toxin group value $(1,092 \mu \mathrm{g}$ OA eq $/ \mathrm{kg}$ e.p.) seven times higher than the allowed legal limit (Table 1). The highest level of toxin $(1,480 \mu \mathrm{g} \mathrm{OA}$ eq $/ \mathrm{kg}$ e.p.) was also found in 2015 , in SGL, at which Dinophysis species were absent.
Most frequently, the increase in OA toxin group contamination was concomitant with a decrease in Dinophysis spp. abundance (Fig. 3a), or even with their absence (Fig. 3b). Only once the highest abundance of Dinophysis in seawater did coincide with the highest levels of toxins in mussels. This occurred in ORO, which was, together with TOR, the site where the OA toxin group was observed more frequently and where Dinophysis reached the maximum cellular abundance.

Toxicity has been mainly observed in the Mytilus galloprovincialis (Lamarck) mussel, while it has been found in rare cases in the other commercial bivalve species (Table 1).

Table 1. Abundance of Dinophysis acuminata and D. sacculus and quantification of okadaic acid toxin group among positive cases of diarrhoetic shellfish poisoning toxicity in 2015 and 2016

\begin{tabular}{|c|c|c|c|c|c|}
\hline \multirow{2}{*}{ Sampling date } & \multirow{2}{*}{ Site Code-station } & \multicolumn{2}{|c|}{ Abundance (cell/L) } & \multirow{2}{*}{$\begin{array}{l}\text { Okadaic acid } \\
\text { toxin group } \\
\text { (mg AO eq } / \mathrm{Kg} \text { e.p.) }\end{array}$} & \multirow{2}{*}{ Shellfish products } \\
\hline & & D. acuminata & D. sacculus & & \\
\hline $23 / 05 / 2016$ & CIR-1 & 0 & 0 & 675.8 & Mytilus galloprovincialis \\
\hline $19 / 02 / 2015$ & COL-1 & 0 & 0 & 341.3 & Mytilus galloprovincialis \\
\hline $09 / 03 / 2015$ & COL-1 & 0 & 0 & 470.4 & Mytilus galloprovincialis \\
\hline $03 / 02 / 2015$ & FER-1 & 0 & 0 & 1,269 & Mytilus galloprovincialis \\
\hline $10 / 02 / 2015$ & FER-1 & 0 & 0 & 263.1 & Mytilus galloprovincialis \\
\hline $19 / 02 / 2015$ & FER-1 & 0 & 0 & 516.2 & Mytilus galloprovincialis \\
\hline $23 / 02 / 2015$ & FER-1 & 0 & 0 & 738.9 & Mytilus galloprovincialis \\
\hline $26 / 02 / 2015$ & FER-1 & 0 & 0 & 317 & Mytilus galloprovincialis \\
\hline $09 / 03 / 2015$ & FER-1 & 0 & 0 & 424.5 & Mytilus galloprovincialis \\
\hline $19 / 03 / 2015$ & FER-1 & 0 & 0 & 383.1 & Mytilus galloprovincialis \\
\hline $23 / 03 / 2015$ & FER-1 & 0 & 0 & 257.2 & Mytilus galloprovincialis \\
\hline $07 / 01 / 2016$ & FER-1 & 1,040 & 120 & 355.8 & Mytilus galloprovincialis \\
\hline $12 / 01 / 2016$ & FER-1 & 1,720 & 40 & 1,111 & Mytilus galloprovincialis \\
\hline $19 / 01 / 2016$ & FER-1 & 0 & 0 & 790 & Mytilus galloprovincialis \\
\hline $02 / 02 / 2016$ & FER-1 & 40 & 0 & 547 & Mytilus galloprovincialis \\
\hline $09 / 02 / 2016$ & FER-1 & 40 & 0 & 778 & Mytilus galloprovincialis \\
\hline $16 / 02 / 2016$ & FER-1 & 0 & 0 & 315 & Mytilus galloprovincialis \\
\hline $19 / 02 / 2016$ & FER-1 & n.s. & n.s. & 273 & Mytilus galloprovincialis \\
\hline $23 / 02 / 2016$ & FER-1 & 40 & 0 & 385 & Mytilus galloprovincialis \\
\hline $03 / 03 / 2016$ & FER-1 & 0 & 0 & 317 & Mytilus galloprovincialis \\
\hline $12 / 01 / 2016$ & FER-2 & 0 & 0 & 660 & Tapes decussatus \\
\hline $27 / 04 / 2015$ & ORO-1 & 1,560 & 0 & 184 & Mytilus galloprovincialis \\
\hline $27 / 04 / 2015$ & ORO-4 & 1,680 & 0 & 205 & Mytilus galloprovincialis \\
\hline $15 / 06 / 2016$ & ORO-4 & 40,200 & 9,400 & 607 & Mytilus galloprovincialis \\
\hline $29 / 06 / 2016$ & ORO-6 & 18,700 & 2,200 & 1,066 & Mytilus galloprovincialis \\
\hline $04 / 07 / 2016$ & ORO-6 & 2,200 & 400 & 371 & Mytilus galloprovincialis \\
\hline $18 / 07 / 2016$ & ORO-6 & n.s. & n.s. & 299 & Mytilus galloprovincialis \\
\hline $25 / 07 / 2016$ & ORO-6 & n.s. & n.s. & 188 & Mytilus galloprovincialis \\
\hline $03 / 02 / 2015$ & SGL-2 & 0 & 0 & 1480 & Mytilus galloprovincialis \\
\hline $19 / 02 / 2015$ & SGL-2 & 0 & 0 & 704.8 & Mytilus galloprovincialis \\
\hline $19 / 02 / 2015$ & SGL-3 & 0 & 0 & 498.8 & Mytilus galloprovincialis \\
\hline $23 / 02 / 2015$ & SGN-4 & 0 & 0 & 618.9 & Mytilus galloprovincialis \\
\hline $12 / 01 / 2016$ & STD-4 & 120 & 0 & 168 & Crassostrea gigas \\
\hline $11 / 02 / 2015$ & TOR-2 & 1,800 & 0 & 192.5 & Mytilus galloprovincialis \\
\hline $11 / 02 / 2015$ & TOR-3 & 142,662 & 37,895 & 1092 & Mytilus galloprovincialis \\
\hline $26 / 02 / 2015$ & TOR-3 & 14,400 & 400 & 188.2 & Mytilus galloprovincialis \\
\hline $11 / 03 / 2015$ & TOR-3 & 2,400 & 0 & 301.3 & Mytilus galloprovincialis \\
\hline $18 / 03 / 2015$ & TOR-3 & n.s. & n.s. & 326.5 & Mytilus galloprovincialis \\
\hline $23 / 03 / 2015$ & TOR-3 & n.s. & n.s. & 181.7 & Mytilus galloprovincialis \\
\hline $15 / 04 / 2015$ & TOR-3 & 9,400 & 0 & 210.2 & Mytilus galloprovincialis \\
\hline $07 / 03 / 2016$ & TOR-1 & n.s. & n.s. & 208 & Mytilus galloprovincialis \\
\hline $14 / 03 / 2016$ & TOR-1 & 200 & 0 & 204 & Mytilus galloprovincialis \\
\hline $07 / 03 / 2016$ & TOR-2 & n.s. & n.s. & 277 & Mytilus galloprovincialis \\
\hline $14 / 03 / 2016$ & TOR-2 & 600 & 0 & 299 & Mytilus galloprovincialis \\
\hline $07 / 03 / 2016$ & TOR-3 & n.s. & n.s. & 190 & Mytilus galloprovincialis \\
\hline $14 / 03 / 2016$ & TOR-3 & 400 & 0 & 200 & Mytilus galloprovincialis \\
\hline
\end{tabular}

n.s.: not sampled 


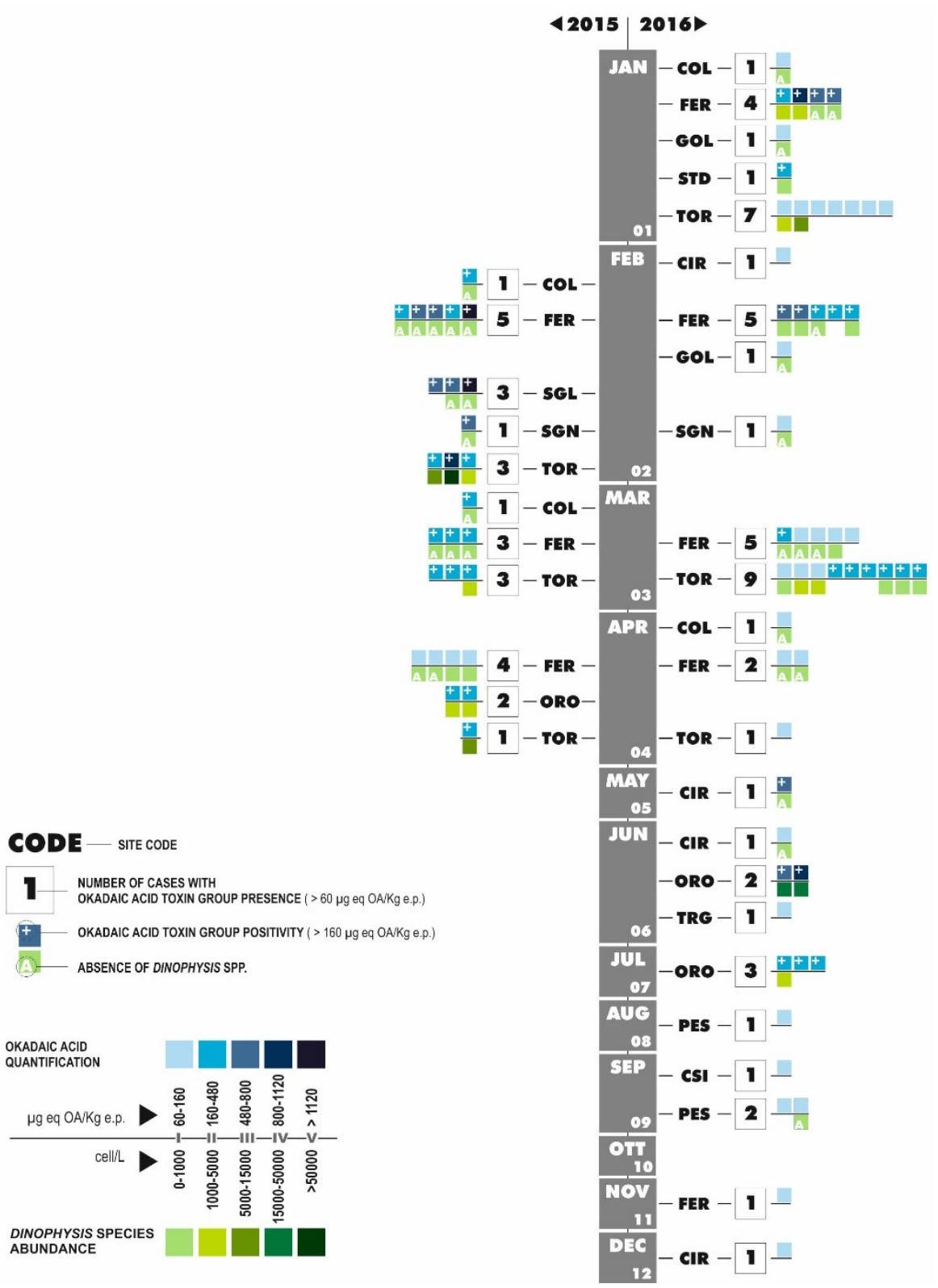

Fig. 2. Monthly numbers of cases (within the bigger squares) with okadaic acid toxin group in shellfish farms (identified with own site codes) during 2015 (left) and 2016 (right). Classes of okadaic acid toxin group quantification (smaller squares above the line) and Dinophysis spp. abundance (smaller squares below the line) are shown. Plus sign indicates values exceeding the legal limit for okadaic acid toxin group concentration. Letter A indicates the absence of Dinophysis spp.

\section{Discussion}

This two year-study performed in a monitoring area of the Mediterranean Sea documented the presence of lipophilic toxins causing DSP syndrome in molluscs. Although the percentage of contaminated samples was very low in some sites, positive shellfish were detected along the entire investigated coast.

Dinophysis species were commonly found throughout various sites during both study years. In particular, D. acuminata was the most geographically widespread dinoflagellate and it showed the highest cell abundance. Results from this study showed a spread of $D$. acuminata similar to those recorded in previous studies (3), but with higher abundance values.
Every time when the OA toxin group was found in molluscs, Dinophysis species were reported in the seawater, even days or weeks before the identification of the toxin accumulation. Therefore, toxin and the potential HAS were not often present at the same time. A direct relationship almost never occurred between Dinophysis spp. cell abundance in seawater and lipophilic toxin concentration in shellfish. A similar discrepancy between the abundance of Dinophysis in the water column and shellfish toxicity was previously recorded during events of DSP occurring in SGL and FER in 2002 and 2003, when the species implicated (D. sacculus, D. caudata, and D. fortii) reached a maximum concentration of $3 \times 10^{3}$ cell/ $/ \mathrm{L}(3)$. 

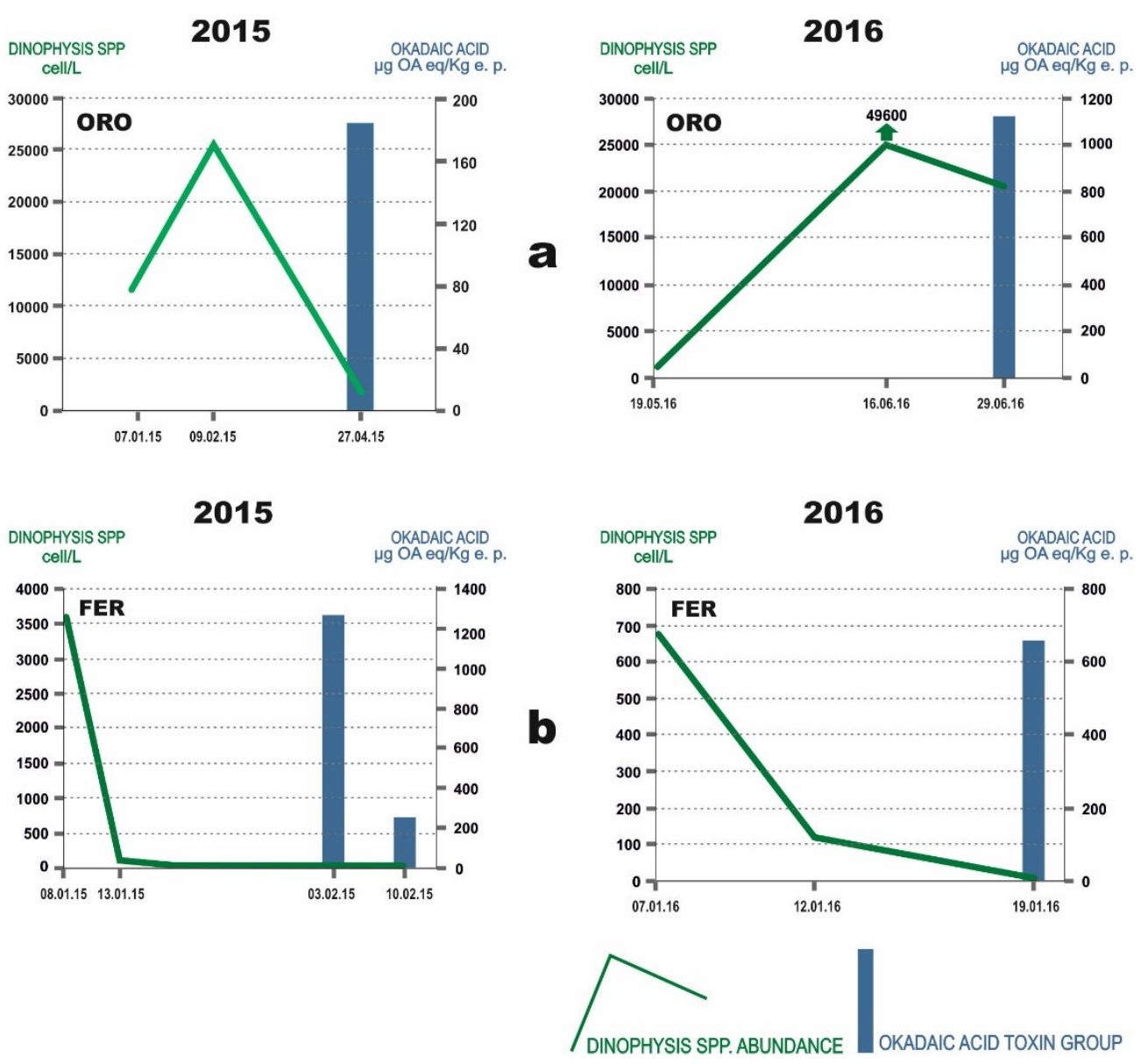

Fig. 3. Examples of the relationship between Dinophysis spp. cell abundance (green line) in seawater and the presence of okadaic acid toxin group (blue bar) in shellfish during 2015 (left side of figure) and 2016 (right side). The X-axis lists the dates of seawater and shellfish sampling; the left-hand Y-axis shows the values of Dinophysis species abundance (cell/L)

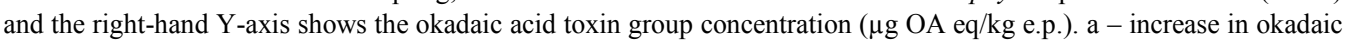
acid toxin group concentration concomitant with a decrease in Dinophysis spp. cell abundance in Orosei (ORO); $\mathrm{b}$ - presence of okadaic acid toxin group concomitant with Dinophysis spp. absence in Feraxi (FER)

Neither physico-chemical and environmental parameters nor the structure of the phytoplanktonic community was analysed in this study; however, several factors, including low salinity, stratification of waters, abundance of non-toxic accompanying species (possible alternative food sources for mussels), and DSP toxin content per Dinophysis cell may be responsible for the lack of temporal association between DSP-positive samples and the abundance of $\operatorname{HAS}(6,12)$. This issue has been described in several reports $(6,29)$ in different geographical areas (the Netherlands and Norway respectively), but it is in contrast with results of other, studies $(30,16)$ which have reported such a relationship.

The OA toxin group was present only between February and April in 2015, but it was recurrent throughout 2016, except for in October (Fig. 2). The numbers of samples with OA concentrations over the legal limit were the same in 2015 and 2016 (23), despite the fact that the toxin was detected over a much longer period in 2016 than in 2015 (February-April in 2015 but January-December in 2016). Only in FER, TOR, and
SGN there was a two-year correspondence in toxin detection from February to April (Fig. 2). The first four months seem to be the most critical period of the year (winter-early spring) for OA contamination due to its continued presence. However, during 2016, toxin positivity also occurred in the late spring-summer period, and in some cases it was rather severe $(e . g$. mussels from ORO showed OA levels above $1,000 \mu \mathrm{g}$ eq $/ \mathrm{kg}$ e.p. at the end of June, coinciding with Dinophysis spp. abundance $>20 \times 10^{3}$ cell/L). Toxins are frequently detected during the winter months in other Mediterranean areas, including Greece (7) and Turkey, where there is a clear seasonal trend (27).

Concurrent with the detection of levels exceeding the mussel toxicity limit, a ban on harvesting and an increased sampling plan (every two days) are implemented in the involved farms. Until the restoration of conformity, additional sampling is performed and the conduct of business by the shellfish industry is prohibited by law. Most toxic events are short-lived (a maximum of a few weeks), with a few exceptions. For 
example, the OA toxin group was present for a long period (from January to April 2016) in FER, with values above the defined threshold for two months (Table 1). The closure of the mollusc farms and the resulting economic losses due to the blocked shellfish harvest have affected a number of areas, including Norway (20), Australia (2), Spain (19), France (13), and Greece (16).

Mussels have caused DSP outbreaks, sometimes quite serious, in several European countries (France, Spain, and Denmark), as well as in Canada, Chile, Argentina, and New Zealand (15 and references therein). This problem has also been reported in Italy. The first cases of gastroenteritis associated with DSP toxin-contaminated shellfish were reported in 1989 in the Northern Adriatic Sea (4). The most serious human intoxications occurred in 2010 when about 300 people in various Italian regions developed food poisoning (5). High toxicity levels related to the OA toxin group were also reported in the same shellfish product at the same time in Sardinia (data not published), but the control measures and the regional alert system ensured the protection of consumers. Despite the persistent presence of the OA toxin group, no reports of DSP intoxications were registered during this two-year monitoring programme.

In conclusion, regular surveys of farmed shellfish have simultaneously monitored for HAS and screened for marine biotoxins. OA was the principal group in the toxin profile of the shellfish samples and was found almost exclusively in M. galloprovincialis. Several DSP toxic episodes occurred over the two-year study period related mainly to Dinophysis species, which resulted in the closure of the farms. On these occasions, the total toxin content often increased when the Dinophysis abundance declined. This inverse relationship demonstrates that the risk of shellfish toxicity can persist even when cell abundance is reduced; therefore, it is important to take this finding into account in monitoring strategies. The results of this monitoring programme suggest that the risk associated with shellfish intoxication in Sardinia has increased in recent years due to the recurrent presence of Dinophysis species, which is implicated in mollusc contamination and the increased occurrence of OA and its derivatives. The monitoring programme does not ascribe shellfish intoxication risk to the widespread distribution of the HAS responsible for PSP and ASP, namely Alexandrium spp. and Pseudo-nitzschia spp. DSP has been occurring more frequently than in the past when PSP was considered the main toxin-related problem. Therefore, although no cases of human intoxication have been reported, continuous surveillance for potentially toxic phytoplankton and toxin bioaccumulation is necessary in order to predict their harmful effects, prevent human poisoning, and manage the negative consequences for aquaculture operators.
Conflict of Interests Statement: The authors declare that there is no conflict of interests regarding the publication of this article.

Financial Disclosure Statement: This study was supported by the Autonomous Region of Sardinia.

Animal Rights Statement: None required.

\section{References}

1. AESAN: EU-Harmonised Standard Operating Procedure for determination of lipophilic marine biotoxins in molluscs by LCMS/MS. Version 5, 2015, European Union Reference Laboratory for Marine Biotoxins, Agencia Española de Consumo, Seguridad Alimentaria y Nutrición,Vigo, Spain.

2. Ajani P., Brett S., Krogh M., Scanes P., Webster G., Armand L.: The risk of harmful algal blooms (HABs) in the oyster-growing estuaries of New South Wales, Australia. Environ Monit Assess 2013, 185, 5295-5316.

3. Bazzoni A.M., Caddeo T., Pulina S., Padedda B.M., Satta C.T., Sechi N., Lugliè A.: Spatial distribution and multiannual trends of potentially toxic microalgae in shellfish farms along the Sardinian coast (NW Mediterranean Sea). Environ Monit Assess 2015, 187, $1-18$.

4. Boni L., Mancini L., Milandri A., Poletti R., Pompei M., Viviani R.: First cases of DSP in the Northern Adriatic Sea. International Conference Regione Emilia Romagna, Bologna (Italy), 1990, 419-426.

5. Ciminiello P., Dell'Aversano C., Forino M., Tartaglione L.: Marine toxins in Italy: the more you look, the more you find. Eur J Org Chem 2014, 1990, 1357-1369.

6. Dahl E., Johannessen T.: Relationship between occurrence of Dinophysis species (Dinophyceae) and shellfish toxicity. Phycologia 2001, 40, 223-227.

7. Economou V., Papadopoulou C., Brett M., Kansouzidou A., Charalabopoulos K., Filioussis G., Seferiadis K.: Diarrhetic shellfish poisoning due to toxic mussel consumption: the first record outbreak in Greece. Food Addit Contam 2007, 24, 297-305.

8. European Commission: Regulation of 26 November 1996, 2406/19964/EC. OJ L 334, 23/12/1996.

9. European Commission: Regulation of 29 April 2004, 853/2004/EC. OJ L 139, 30/04/2004.

10. European Commission: Regulation of 10 January 2011, 15/2011/EC. OJ L 6, 10/01/2011.

11. Fabro E., Almandoz G.O., Ferrario M., Tillmann U., Cembella A., Krock B.: Distribution of Dinophysis species and their association with lipophilic phycotoxins in plankton from the Argentine Sea. Harmful Algae 2016, 59, 31-41.

12. Godhe A., Svensson S., Rehnstam-Holm A.S.: Oceanographic settings explain fluctuations in Dinophysis spp. and concentrations of diarrhetic shellfish toxin in the plankton community within a mussel farm area on the Swedish west coast. Mar Ecol Prog Ser 2002, 240, 71-83.

13. Hossen V., Jourdan-da Silva N., Guillois-Bécel Y., Marchal J., Krys S.: Food poisoning outbreaks linked to mussels contaminated with okadaic acid and ester dinophysistoxin-3 in France, June 2009. Eurosurveillance 2011, 16, 1-7.

14. Intergovernmental Oceanographic Commission (IOC-UNESCO): Taxonomic Reference List of Harmful Micro Algae. http://www.marinespecies.org/hab.

15. James K.J., Carey B., O’Halloran J., van Pelt F.N.A.M., Skrabakova Z.: Shellfish toxicity: human health implications of marine algal toxins. Epidemiol Infect 2010, 138, 927-940.

16. Koukaras K., Nikolaidis G.: Dinophysis blooms in Greek coastal waters (Thermaikos Gulf, NW Aegean Sea). J Plankton Res 2004, $26,445-457$. 
17. Lorenzoni G., Arras I., Sanna G., Delogu P., Mudadu A., Piras A., Mura A., Marongiu E., Virgilio S.: Paralytic shellfish poison algal biotoxins: Sardinia report 2002-2011 and non-compliance management. Ital J Food Saf 2013, 2, 104-108.

18. Lugliè A., Satta C.T., Pulina S., Bazzoni A.M., Padedda B.M., Sechi N.: Harmful algal blooms in Sardinia. Biol Mar Medit 2011, $18,2-9$.

19. Moita M.T., Pazos Y., Rocha C., Nolasco R., Oliveira P.B.: Toward predicting Dinophysis blooms off NW Iberia: a decade of events. Harmful Algae 2016, 53, 17-32.

20. Naustvoll L.J., Gustad E., Dahl E.: Monitoring of Dinophysis species and diarrhetic shellfish toxins in Flødevigen Bay, Norway: inter-annual variability over a 25 -year time series. Food Addit Contam 2012, 29, 1605-1615.

21. Padedda B.M., Pulina S., Magni P., Sechi N., Lugliè A.: Phytoplankton dynamics in relation to environmental changes in a phytoplankton-dominated Mediterranean lagoon (Cabras Lagoon, Italy). AIOL J 2012, 3, 147-169.

22. Reguera B., Pizarro G.: Planktonic dinoflagellates that contain polyether toxins of the old "DSP complex"'. In: Seafood and Freshwater Toxins. Pharmacology, Physiology, and Detection, edited by L.M. Botana, CRC Press, Boca Raton, 2008, pp. 257-284.

23. Reguera B., Riobó P., Rodríguez F., Díaz P.A., Pizarro G., Paz B., Franco J.M., Blanco J.: Dinophysis toxins: causative organisms, distribution and fate in shellfish. Mar Drugs 2014, 12, 394-461.
24. Reguera B., Velo-Suárez L., Raine R., Park M.G.: Harmful Dinophysis species: a review. Harmful Algae 2012, 14, 87-106.

25. Sannio A., Lugliè A., Sechi N.: Potentially toxic dinoflagellates in Sardinia. Plant Biosyst 1997, 131, 73-78.

26. Sardinia Region: Regional plan for the surveillance and sanitary control of the production and marketing of live bivalve molluscs and for the periodic monitoring of production areas of live bivalve molluscs (123 pp.), 2015, Regione Sardegna, Italy (Regulation in Italian).

27. Turki S., Dhib A., Fertouna-Bellakhal M., Frossard V., Balti N., Kharrat R., Aleya L.: Harmful algal blooms (HABs) associated with phycotoxins in shellfish: What can be learned from five years of monitoring in Bizerte Lagoon (Southern Mediterranean Sea)? Ecol Eng 2014, 67, 39-47.

28. Utermöhl H.: Zur vervollkommung der quantitativen phytoplankton-methodik. Verh Int Verein Theor Angew Limnol 1958, 9, 1-39.

29. Van der Fels-Klerx H.J., Adamse P., Goedhart P.W., Poelman M., Pol-Hofstad I.E., van Egmond H., Gerssen A.: Monitoring phytoplankton and marine biotoxins in production waters of the Netherlands: results after one decade. Food Addit Contam 2012, 29, 1616-1629.

30. Villalobos L.G., Santinelli N., Sastre V., Krock B., Esteves J.L.: Dinophysis species associated with diarrhetic shellfish poisoning episodes in North Patagonian Gulfs (Chubut, Argentina). J Shellfish Res 2015, 34, 1141-1149. 